\title{
Evidence of past dental visits and incidence of head and neck cancers: a systematic review and meta-analysis
}

\author{
Bhawna Gupta ${ }^{1^{*}} \mathbb{D}$, Narinder Kumar ${ }^{2}$ and Newell W. Johnson ${ }^{3}$
}

\begin{abstract}
Background: Regular/frequent dental visits, at least annually, can aid in reducing the public health burden of head and neck cancers (HNCs) by facilitating earlier detection of the disease. The aim of this study was to conduct a quantitative assessment of any independent association between past dental visits/check-ups and incidence of cancers of HN/upper aerodigestive tract (UADT) and oral cavity worldwide.
\end{abstract}

Methods: PubMed, CINAHL, and Cochrane databases were searched for all observational studies published until August 2017 in any language that assessed an association of past dental visits/dental check-ups among the incident cases of HNC/UADT cancers. Screening and quality assessment of the articles was performed by two independent reviewers. Three different meta-analyses were conducted: two based on the incident cancer reported in the studies (HNCs/cancers of UADT and oral cavity); another included all studies irrespective of the type of cancer reported with the frequency of past dental visits as subgroups.

Results: Searches retrieved 3164 titles: after removing duplicates, 1377 remained. Of these, 62 were reviewed in full, but only 38 were eligible for inclusion. Under the random effects model, odds of past never/irregular/ not frequent dental visits were greater in HNC cases and oral cancer cases as compared to the hospitalbased/population-based controls [HNCs-unadjusted odds ratio (OR) 2.24; 95\% confidence interval (Cl) 1.89 to 2.65) and (oral cancers-OR 1.93; 95\% Cl 1.47 to 2.52]. Similar results were observed for all cancers with frequency of past dental visits as subgroup analysis (OR 2.01; $95 \% \mathrm{Cl} 1.76$ to 2.30). Meta-regression findings indicate that none of the subgroup influenced the effect estimates for incidence of cancers. There was no publication bias in our study.

Conclusion: This systematic review and meta-analysis indicates that individuals with never/irregular/not frequent dental visits are more likely to be incident cases of HNCs/UADT cancers.

Keywords: Oral cancers, Head and neck cancers, Upper aerodigestive tract cancers, Dental visits, Dental check-ups, Systematic review and meta-analysis

\section{Introduction}

Routine/frequent dental visits can aid in detection of head and neck cancers (HNCs) at an early stage [1-4]. More than $90 \%$ of HNCs are squamous cell carcinomas that arise from the mucosal lining of the upper aerodigestive tract (UADT). As defined by the World Health Organization International Classification of Disease (ICD-10 version 2015), cancers of oral cavity (C00-06),

\footnotetext{
* Correspondence: bhawna.gupta@laureate.edu.au

${ }^{1}$ Torrens University, Adelaide, South Australia 5000, Australia

Full list of author information is available at the end of the article
}

oropharynx (C010), hypopharynx (C13), larynx (C32), and esophagus (C15) are collectively known as UADT cancers [5]. Although oral cancers (OCs: the commonest site of HNC worldwide) can be detected early with a simple oral examination as compared to cancers that involve more elaborate screening tests (i.e., breast, prostate, and colon), the rate of early diagnosis of OCs has not improved over time with advanced disease at presentation ranging from 27 to $77 \%$ across the globe [6].

In high-risk populations, some OCs may be preventable through identification of oral potentially malignant

(c) The Author(s). 2019 Open Access This article is distributed under the terms of the Creative Commons Attribution 4.0 International License (http://creativecommons.org/licenses/by/4.0/), which permits unrestricted use, distribution, and 
disorders by general dental practitioners facilitating diagnosis at an early stage, thus initiating the first line of treatment, enabling better treatment outcomes, and lowering the cost of care [7]. Diagnosis of cancer at an early stage can thereby improve survival rates in addition to obtaining better function and esthetics for patients. Visual examination and palpation are the standard mode of OCs screening in wide-spread use. Such opportunistic screening for OCs in both high- and low-risk patients during routine dental check-ups is more likely to be cost-effective in comparison to systematic population-based screening programmes $[8,9]$. Dentists may be particularly well-suited to perform such oral cavity examinations due to their scientific training with the oral anatomy and professional access to the oral cavity [10]. However, OCs are often not conspicuous and thus early detection requires great skill and care, necessitating an informed pool of dentists to conduct thorough examinations on a regular basis among high-risk patients [11-13].

The present systematic review and meta-analysis aims to critically appraise data from comparable observational studies published in any part of the world, leading to a quantitative summary of the scientific evidence of past dental visits versus never dental visits and its association with the incidence of cancers of HN/UADT and oral cavity worldwide. To the best of our knowledge, there is no previously published systematic review and meta-analysis on this topic.

\section{Materials and methods}

We followed the Preferred Reporting Items for Systematic Review and Meta-Analysis (PRISMA) strategy [14]. We have used the critical appraisal skills programme checklist to systematically assess the relevance and results of published papers (https://casp-uk.net/). Case-control, prospective and retrospective cohort, cross-sectional, and screening studies that assessed an association between past dental visits/dental check-ups among the incident cases of HNC and UADT cancers were considered for inclusion. This meta-analysis is based on MOOSE guidelines: Meta-analysis of Observational Studies in Epidemiology [15].

\section{Literature search strategy}

We identified all the published studies using an extensive search of the PubMed, CINAHL, and the Cochrane database from the inception of relevant database until August 2017. The following search terms were used with Boolean operators to combine searches: ("oral cancers" OR "cancers of head and neck" OR "cancer of tongue" OR "cancer of oropharynx" OR "cancer of hypopharynx" OR "cancer of esophagus OR cancers of the UADT" AND "dental visits" OR "visits the dentist" OR "dental check-up" OR "dental examination" OR "dental treatment" OR "dental care" OR "oral hygiene" OR "periodontitis") with no limitations on year of publication and language (Table 1). A health librarian reviewed and provided input on the search strategy. Additional search strategies included (i) a hand search of the reference lists of included studies, (ii) the use of the "related citations" feature in PubMed, (iii) an ongoing surveillance of the literature while updating the manuscript, and (iv) authors were contacted for the articles for which full text was not available. EndNote software was used to remove the duplicates for the same type of article in more than one database. Alerts with search strategies were created in the databases to maintain an ongoing surveillance of the literature.

\section{Study inclusion and exclusion criteria}

To be eligible for inclusion, the paper had to report a primary study with any population, one or both genders specified, participants of any age, incidence of any cancer subsite of HN, and UADT reported as the health outcome, frequency of dental visits/check-ups prior to the diagnosis of one of these cancers (assessed as the exposure), and availability of sufficient data to estimate the measure of association, i.e., unadjusted odds ratio (OR) along with its corresponding 95\% confidence interval (CI). Where a single study was described in several publications, the study which reported the incidence data most comprehensively was included in the analysis. Gray literature, such as unindexed or unpublished conference proceedings, pre-prints, and state of art reports, were not included due to limited resources to access the same.

\section{Data extraction}

Two reviewers (B.G. and N.K.) independently screened the title and abstract of the identified citations. Full texts of citations judged as potentially eligible were acquired by at least one of the two reviewers. Thereafter, both the reviewers used a standardized and pilot-tested form to independently screen every full text for eligibility. Disagreements were resolved by consensus among the authors. Data extraction from individual studies included information on first author's last name, year of publication, region of study, study design, number of cases and controls (or number of participants and events), population characteristics (gender and age), exposure definition (frequency or reason of dental visits which were defined as never/only when in pain, every 6 months or less and every 6-12 months, less than once a year and more than once a year, $1-2$ in a year, $3-5$ in a year and $>5$ in a year, $\geq$ once every 5 years versus $<$ once every 5 years, never versus yes, no regular/special dental care versus regular/special dental care), definition of cancer site, its subsite and its diagnostic/confirmation criteria, method of selection of controls (hospital/population based), adjusted covariates in the regression model, and risk measure in each reviewed article. 


\section{Quality assessment}

Studies were assessed for methodological quality using the quality assessment tool for quantitative studies developed by the Effective Public Health Practice Project (EPHPP) [16]. This tool has six components (selection bias, study design, confounders, blinding, data collection method, withdrawals, and dropouts). Based on this criterion, a global rating as strong, moderate, or weak was assigned to each study based on the no weak rating, one weak rating, and two or more weak ratings for any of the above mentioned six components, using the criteria described in the EPHPP dictionary itself.

\section{Summary measure and data synthesis}

A random effects model was employed in all meta-analysis procedures which produces results that generalize to a range of populations and to different study designs in addition to accounting for heterogeneity between studies. Forest-plots were used to demonstrate the effect of each study and the summary effect size. For effect size estimates, standard errors of its logarithm were calculated from the reported or estimated CIs, assuming that the effect size was log-normally distributed. The logarithms of the effect sizes and their corresponding standard errors formed the data points for random effects meta-analysis. For each analysis, heterogeneity was assessed using by Cochran's $Q$ statistic (measure of weighted square deviations), with $\mathrm{N}-1$ degrees of freedom (where $N$ is the number of studies), results of statistical test based on $\mathrm{Q}$ statistic, between studies variance (T2), and ratio of the true heterogeneity to total observed variation $\left(I^{2}\right)$. We conducted sensitivity analysis by dropping one study at a time and examining its influence on the summary effect estimates. To investigate publication bias, funnel plots were constructed, plotting the logarithmically transformed ORs against the standard error of the associated log OR. The distribution of study risk estimates across the funnel plot was examined visually and Egger's test for small study effects was performed to assess the degree of asymmetry. Comprehensive meta-analysis software was used for all analyses [17]. Unadjusted effect estimates were used in the meta-analysis as the confounding variables used in the multivariate regression model varied significantly between studies. However, unadjusted OR could not be computed for two studies due to limited data on number of cases and controls $[18,19]$.

The classification of exposure variable (history and frequency of past dental visits prior to the diagnosis of cancer for cases and disease/date of interview for the hospital or the population based controls) differed between studies, with few studies reporting more than two categories. In the second situation, a single effect estimate was computed by comparing the frequency of dental visits in highest category versus the pooled data from the other categories.

Studies that evaluated cancers of the HN/UADT and oral cavity were pooled in two separate evaluations. Some studies presented data on both HNCs as well as OCs and were included in both evaluations. Two different meta-analyses were conducted based on the health outcome as reported by the authors in the articles: one for HNCs/UADTCs and the other meta-analysis was conducted based on OCs exclusively. To report the pooled effect of frequency of dental visits on incidence of cancers, the exposure variable was categorized as yes/ regular/frequent (subjects in highest category of dental visits in each study) and never/irregular/not frequent (other dental visits categories of each study). A third meta-analysis was executed by pooling the data from all the studies irrespective of the cancers with the frequency of dental visits as subgroup. Three studies could not be included in any of the other subgroups and shared individual identity for subgroups.

\section{Results}

The detailed process of the literature search and article screening is described in Fig. 1. The database and the hand search of the reference list yielded 3170 publications. The databases used as sources for studies were PubMed $(n=2970)$, CINAHL $(n=185)$, and Cochrane Library $(n=9)$. A total of 1377 articles remained after excluding 1793 duplicate records. A further 1315 articles were excluded after study of the abstracts, leaving 62 for which the full texts were assessed for eligibility. The systematic review finally included 38 articles after excluding 24 articles due to unrelated outcome, frequency of dental visits not given for cases and controls to estimate the effect size, study design other than case-control, review articles, letter to editor or comments, similar data from same study population presented in another manuscript, and sample size less than 50. Finally, a total of 26 case-control studies were included in the meta-analysis. The summary and the characteristics of these articles are presented in Tables 2 and 3.

\section{Characteristics of included articles}

Overall, this systematic review includes 32 case-control and 6 other design studies not limited to cross-sectional, observational, case-series, and screening. Fourteen of these studies were conducted in Europe [20-33]. There were nine studies conducted in North America [1, 2, 4, 18, 34-38], five in South America [39-43] nine in Asia [44-52], and a single study in Australia [53]. For the meta-analysis, 16 case-control studies had hospital-based 


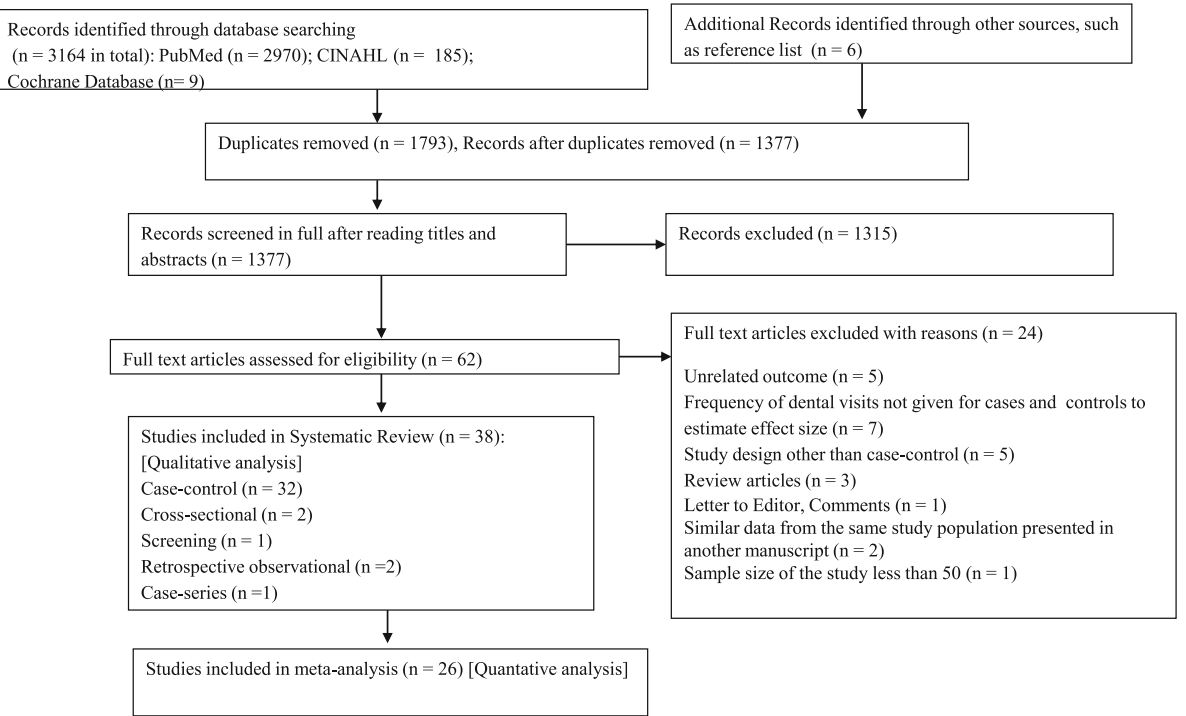

Fig. 1 Flowchart diagram of literature search according to Preferred Reporting Items for Systematic Review and Meta-Analysis guidelines

controls $[2,20,23,27,28,30,36,39,41,43-45,48,50$, $52,54,55]$, seven had population-based controls [18, 24, $29,34,35,47,56]$, and two studies had both hospitaland population-based controls [22, 40]. There was one study on OCs conducted in India, and this did not provide the source, nor describe the type of controls [49].

Among the studies included in the meta-analysis, 11 were based on HNCs and 13 studies included OCs as the health outcome (details of same available in Tables 2 and $3)$. Only two studies included both HNCs and cancers of the esophagus [22, 24]. The studies with HNCs/UADTCs represented a total sample size of 38,552 including 17,313 cases and 21,239 controls. The studies with OCs represented a total sample size of 22,542 including 10,982 cases and 22,542 controls. All the studies included both males and females with one exception which included only females, this being conducted in China with OCs as the health outcome [44]. The overall age group of the study participants ranged from $<20$ to $\geq 80$ years. Dental visits as never/only when in pain or less than once a year and more than once a year were reported in 11 studies. One study reported frequency of dental visits as $1-2$ in a year, $3-5$ in a year, and $>5$ in a year. Never, only when in pain, and regular dental visits were reported in one study. Never, every 6 months or less, and every 6-12 months dental visits were reported in three studies. Dental visits as never, $<$ every 5 years, every $2-5$ years, and at least every year were reported in three studies. Never, $\geq$ once every 5 years versus < once every 5 years dental visits were reported in two studies. Dental visits as never versus yes were reported in four studies. No regular/ special dental care versus regular/special dental care was used in one study.

\section{Quality assessment}

Majority of the studies (29) were of strong quality. Moderate quality was assessed for seven studies and three studies were assessed as weak (Table 4).

\section{Meta-analysis for HNCs/UADTCs}

The odds of never/irregular/not frequent dental visits as compared to yes/regular/frequent dental visits were greater among the cases as compared to controls. Never/ irregular/not frequent dental visits increased the risk of cancer significantly. Under the random effects model, the overall pooled estimate risk for cancer was (OR 2.24; 95\% CI $1.89,2.65, P<0.001)$. The test for heterogeneity produced Tau square of $0.00, Q=38.25, I^{2}=34.63 \%$, test for overall effect $z=8.81,(P<0.001)$. The highest risk estimates observed were (OR 11.89; 95\% CI 3.33, 42.51, $P<$ 0.001 ) in a study conducted in Poland from 1997 to 2000. However, the wide CIs indicate the small sample size of the study. We did not find any statistically significant results for three studies (Fig. 2).

\section{Meta-analysis for OCs}

The odds of never/irregular/not frequent dental visits as compared to yes/regular/frequent dental visits were higher among the cases as compared to controls indicating a statistically significant increase in the cancer. Under the random effects model, the overall pooled 
estimate risk was (OR 1.93; 95\% CI 1.47 to $2.52, P<$ $0.001)$. The test for heterogeneity produced Tau square of $0.00, Q=15.96, I^{2}=24.83 \%$, test for overall effect $z=$ 4.76, $(P<0.001)$. Highest risk was found in a study conducted in Taiwan on 287 cases and 296 controls (OR 6.47; 95\% CI 3.78 to $11.09, P<0.001$ ) (Fig. 3). We also observed that yes/regular/frequent dental visits showed protective effect and decreased the incidence of $\mathrm{OC}$ by $52 \%$. The overall pooled estimate risk for cancer was (OR 0.48; CI 0.38 to $0.60, P<0.001$ ), data not shown.

\section{Meta-analysis for HNCs/UADTCs by subgroup analysis}

The studies were divided into various subgroups according to reported frequency of dental visits in respective studies as follows: (Never $/ \leq 6$ months, $>6$ months); (Never, < once a year, $\geq$ once a year); (Never, yes); (Special dental care); (only in pain, no visits); (1-2 visits a year, 3-5 visits a year). Figure 4 illustrates the subgroup analysis by frequency of past dental visits in these studies. The overall pooled estimate risk was (OR 2.01; 95\% CI 1.76 to $2.30, P<0.001)$. The test for heterogeneity produced Tau square of $0.00, Q=36.33, I^{2}=31.76 \%$, test for overall effect $z=9.24,(P<0.001)$.

\section{Publication bias and meta-regression}

The symmetrical funnel plot in Fig. $5 \mathrm{a}-\mathrm{c}$ by visual inspection for frequency of dental visits and incidence of HNCs/UADTCs and OC indicates that there was no publication bias in our meta-analysis. The Egger's regression intercept was -0.9849 , standard error = $0.8461,95 \%$ CI -2.73 to $0.76, t=1.16, \mathrm{df}=24$, and $P=$ 0.2558 . Publication bias for studies conducted on OCs shows Egger's regression intercept $=-1.3239$, standard error $=1.7850,95 \% \mathrm{CI}-5.25$ to $2.60, t=0.7416, \mathrm{df}=11$, and $P=0.474$. For all the studies included in meta-analysis and grouped by the frequency of dental visits: the Egger's regression intercept was -0.889, standard error $=0.8946,95 \% \mathrm{CI}-2.73$ to $0.9941, t=$ 0.9940, $\mathrm{df}=24$, and $P=0.330$. Results of meta-regression analysis indicate that none of the included subgroups for history of dental visits influenced the effect estimate (Table 5).

\section{Discussion}

In this meta-analysis, we aimed to quantify the effect of frequency of dental visits on incidence of HNCs/UADTCs and OCs. To the best of our knowledge, this is the first systematic review and meta-analysis on this topic. All the included 26 studies in meta-analysis were hospital- or population-based case-control studies, which included history of dental visits among incident cancer cases. Our meta-analysis irrespective of the frequency of past dental visits indicates a significant association between lack of dental visits (never/irregular/not frequent) and incidence of HNCs, particularly so for OCs. This may be partly attributed to the hypothesis that individuals not visiting the dentists for oral check-ups are ignorant of their oral hygiene and any potentially malignant changes in their oral

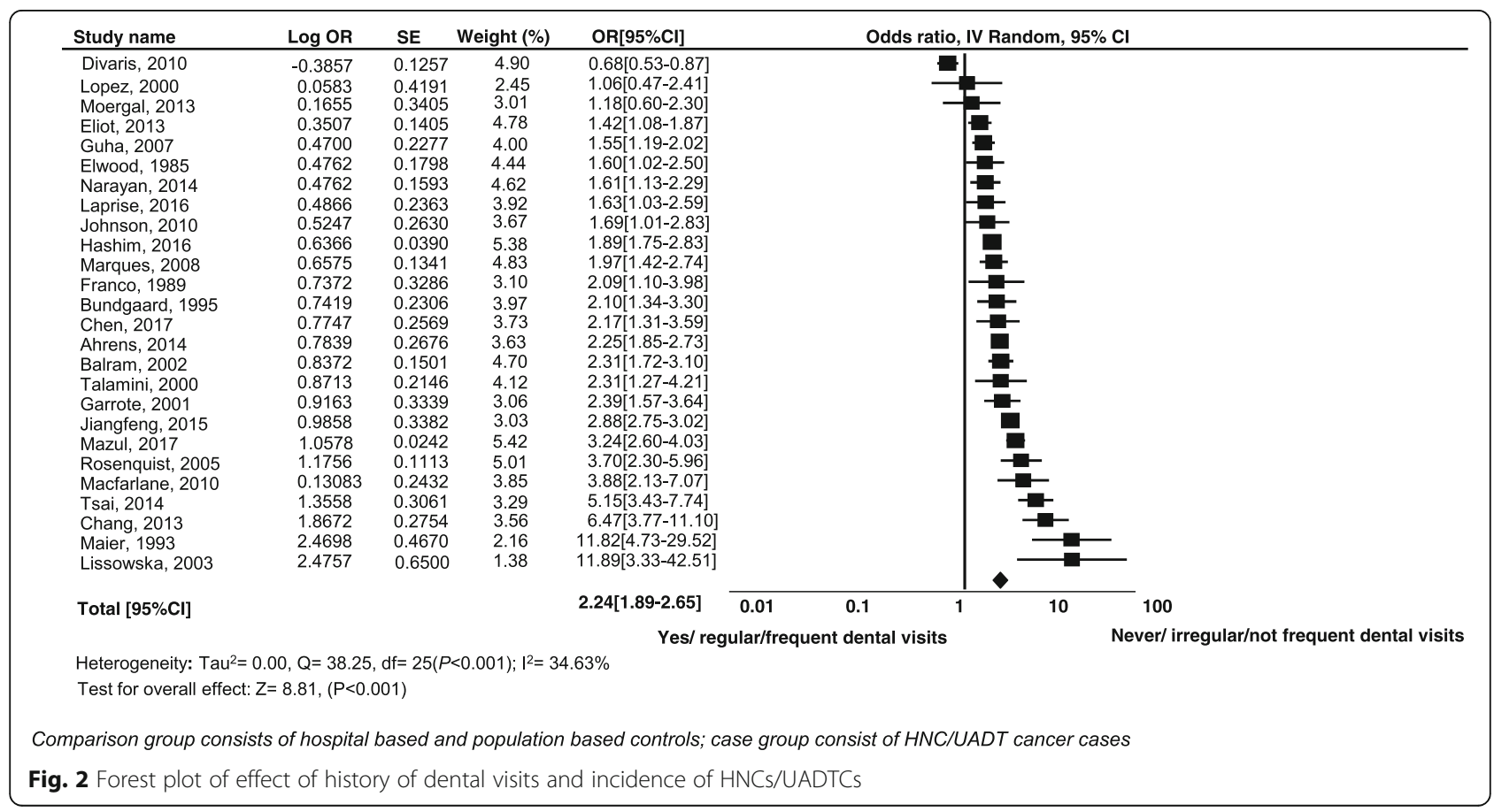




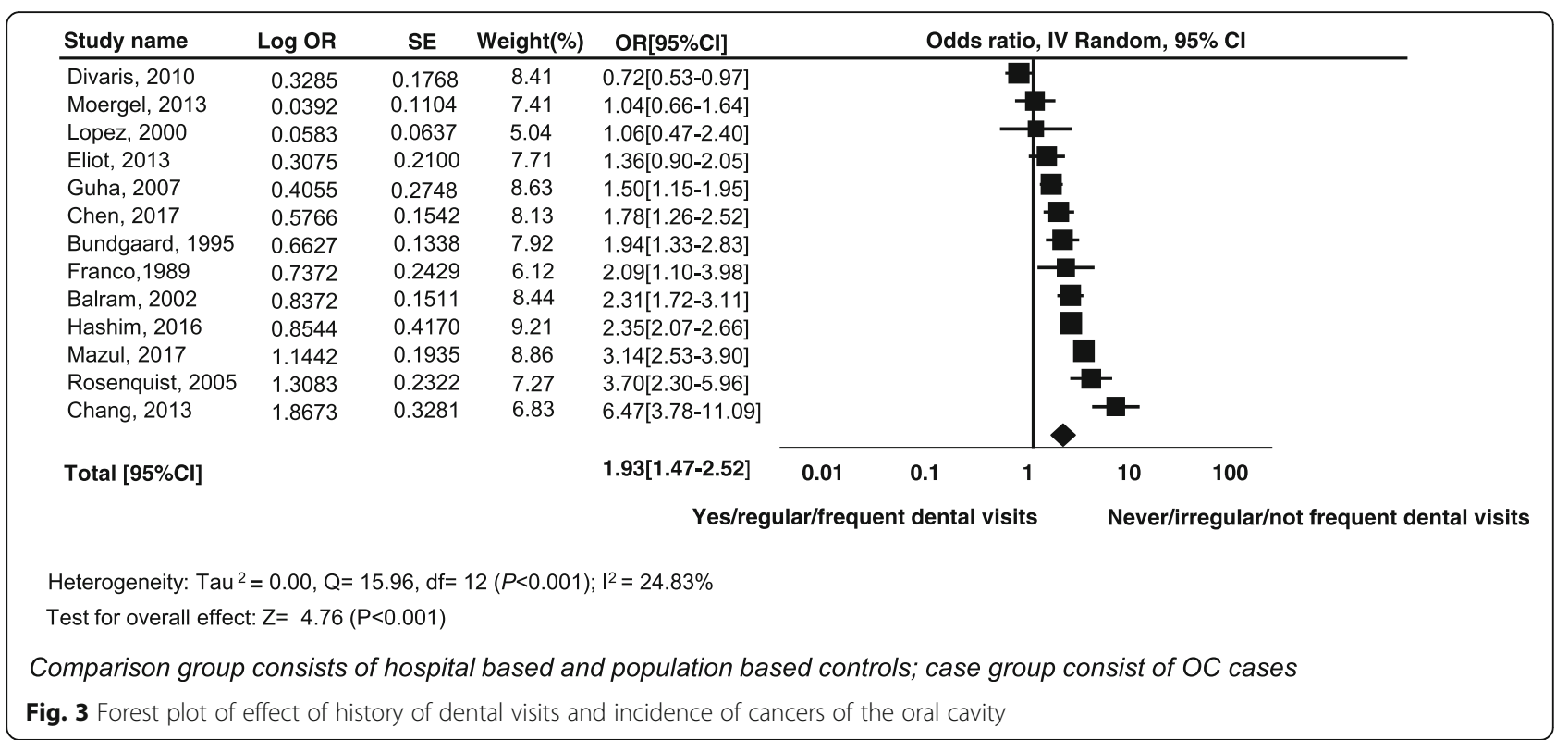

cavity. Other reasons could be perceived lack of need, affordability, limited resources, and limited availability of oral health care providers and populations with low gross national income per capita.

Lack of dental visits on regular or frequent basis has been posited to contribute to the incidence of, and outcomes for HNCs, as a synergistic and independent variable [20, 40,53]. Several studies report that subjects who had never made any dental visits had a higher risk of OCs than subjects who reported visiting at least once a year $[2,27,37,40,42,50,51,56,57]$. Two studies indicate significant increase in the risk of OCs in the absence of dental visits among women only [44, 52].

Results of a case-series on 441 incident cases of oral and oropharyngeal cancer in the Greater Boston area reports that never or rarely going to the dentist was associated with being diagnosed at higher stage (cumulative $\mathrm{OR}=2.28,95 \% \mathrm{CI} 1.02$ to 5.10 and cumulative $\mathrm{OR}=$ 9.17, 95\% CI: 2.70 to 31.15$)$ compared to those going to the dentist at least annually [4]. The Carolina head and

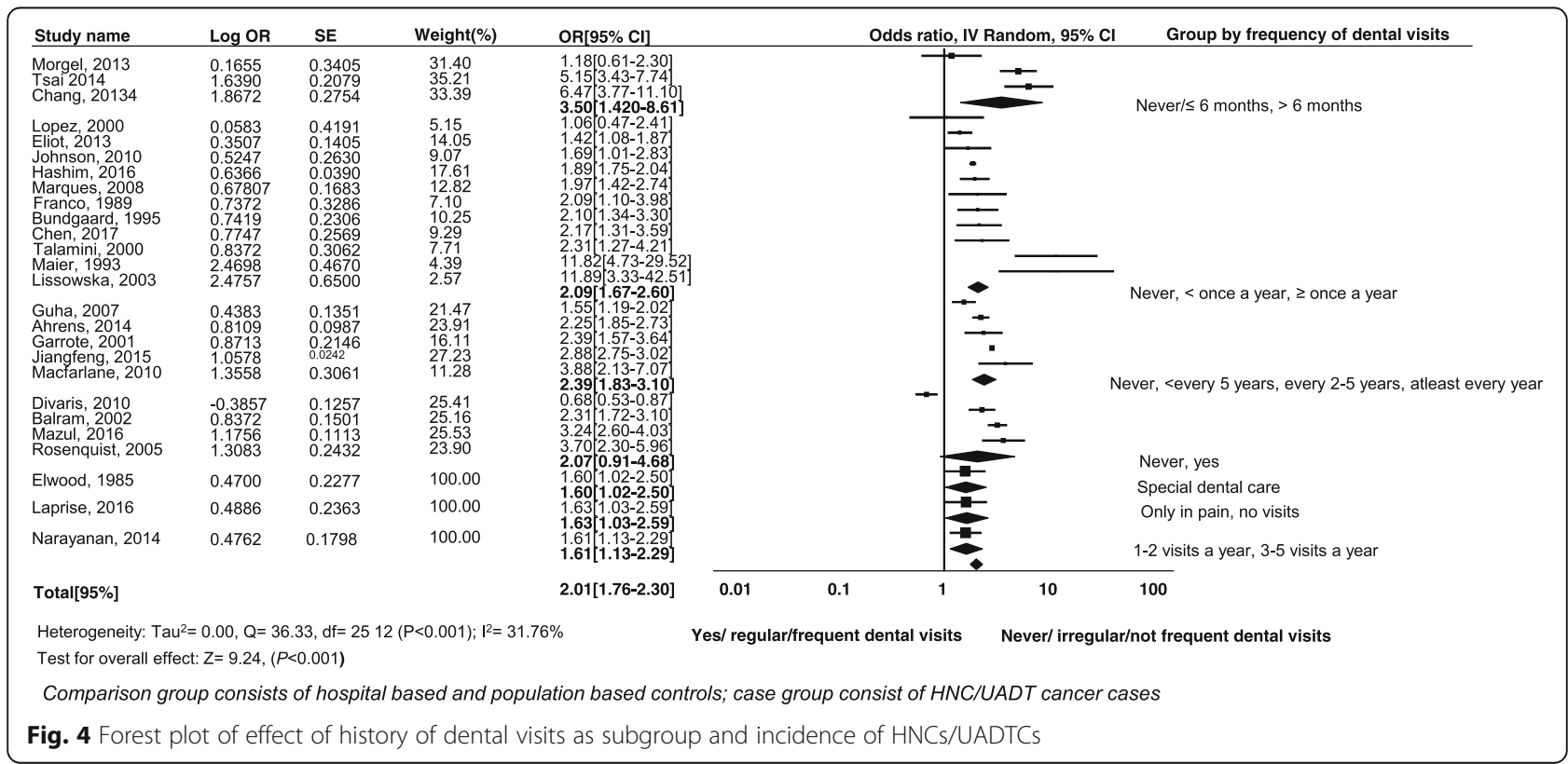




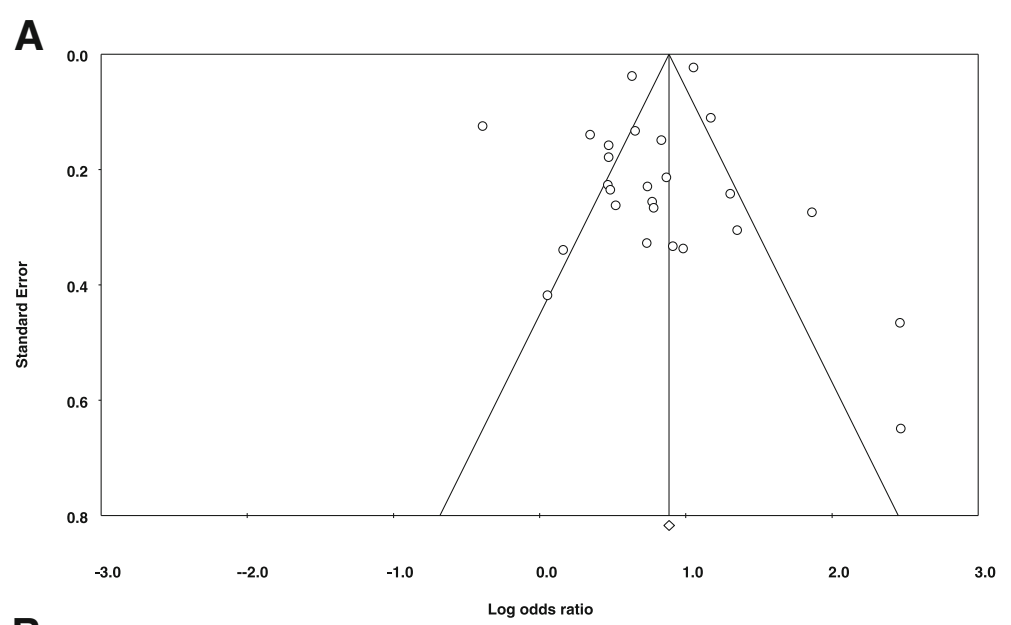

B

Log odds ratio

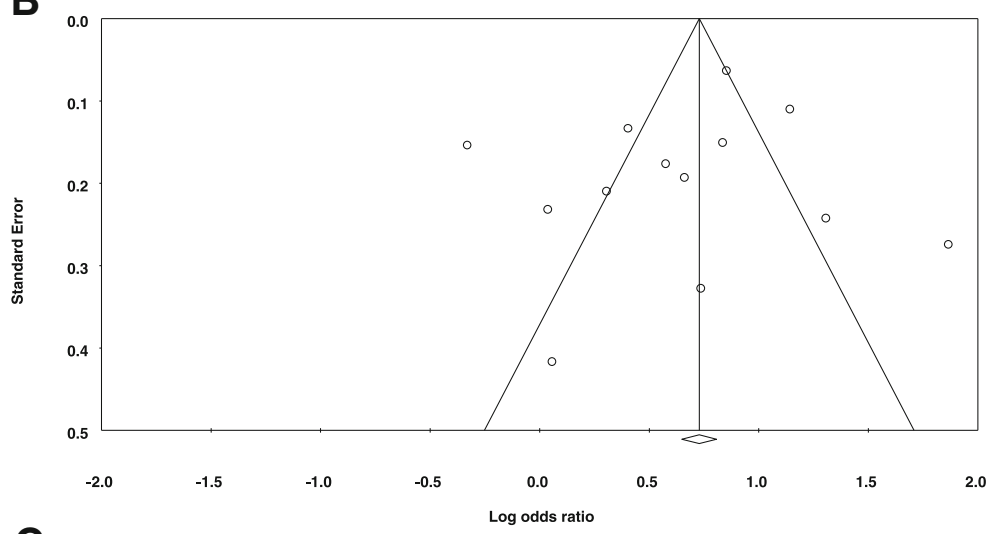

C

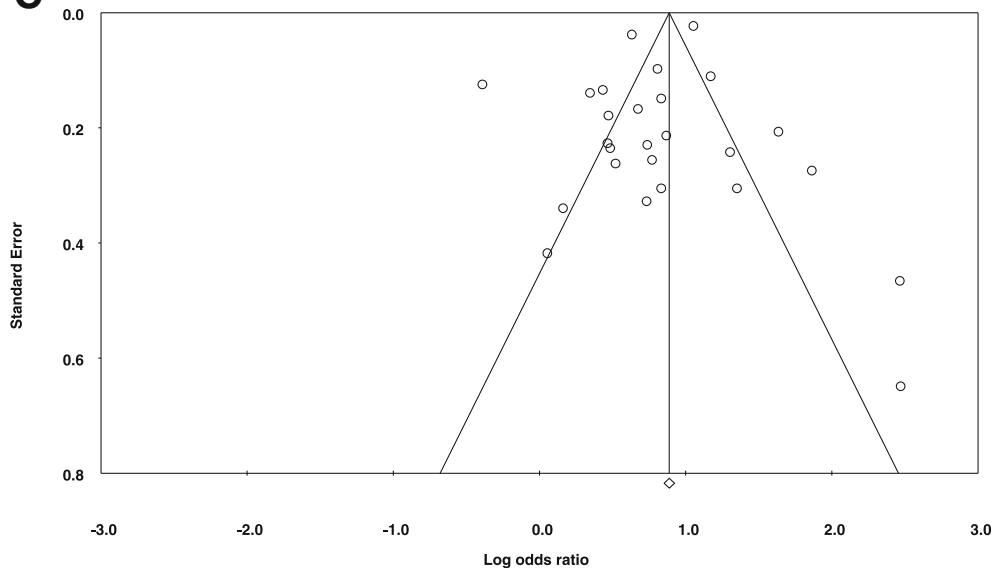

Fig. 5 a Funnel plot of standard error by Log odds ratio for all HNCS/UADTCs case-control studies. b Funnel plot of standard error by log odds ratio for all OCs case-control studies. c Funnel plot of standard error by log odds ratio for all HNCS/UADTCs studies grouped by frequency of dental visits

neck cancer population-based case-control study found a $32 \%$ decrease in oral, pharyngeal, and larynx cancers among those who had a history of more than one or more routine dental visits in the past ten years from the date of diagnosis of cancer [18].

Pooled analysis of 8925 incident cases of HNCs and 12,527 controls of 13 INHANCE case-control studies found $26 \%$ reduction in incidence of OCs among the patients who made one or more than one annual visits for dental check-ups [20]. This result of substantial decrease in the risk of OCs associated with regular or routine dental visits is in concordance with a substantial body of previous epidemiological studies [24, 29, 30, 33, 37, 39-41, $43,52,56]$. However, there are studies which do not report 
any significant positive association between dental visits and incidence of OCs $[23,28,40]$. Mazul et al. supported the evidence that routine dental examinations were significantly associated with decreased risk of all UADT cancer subsites [34].

We have made every effort to include all case-control studies with adequate sample size $(N>50)$ so that the statistical power and precision of analysis in this paper are strong, and ensure generalizability of our results. Furthermore, majority of the studies we have chosen are of sufficiently good quality.

Our findings have wider clinical implications. Regular or frequent dental check-ups, with oral hygiene advice and interventions, will aid in maintaining a health-associated oral flora, reducing the load of potential pathogens. Dentists can expedite early detection of OCs and move a patient quickly into available management pathways. There have been statistically significant differences in the percentage of OCs identified by the dentists and oral maxillofacial surgeons in comparison to the medical physicians in regions like Australia and Europe [32, 53, 58]. Similarly, there is an abundant evidence for dentists in contrast to the physicians making referral for OCs at an early stage [3, 53, 59-63]. Several past studies add to the referral pattern of the OCs patients made by the dental practitioners at an early stage embarking the significant role of dentists in disease detection [63-69].

Langevin et al. in a population-based case-control study of HNCs in the greater Boston area and Holmes et al. in a retrospective study in a central European population have reported that oral and oropharyngeal cancers were diagnosed at an early stage at dental offices, compared to physician's offices [4, 62]. Concurrently, a study conducted on 131 incident cases of oral and oropharyngeal cancers in Florida showed that regular dental visits were associated with $65 \%$ of cancers being diagnosed at an early stage [1].

Routine opportunistic screening is long recommended for all dentists as they have access to full mouth examination during routine dental check-ups and are well aware of normal oral anatomy [70]. There is evidence for support from a retrospective cohort analysis in Canada on 2331 incident cases of squamous cell carcinoma of anterior tongue and floor of mouth that the dentists were more likely to have detected the cancer through a screening exam (15\% compared to $1.4 \%$ referred by a family doctor) [3]. Nonetheless, OCs in its initial stage is not always clinically detectable and requires special skills, including palpation of suspect tissues $[11,71,72]$ Continuing education programmes for dentists for early detection of OCs are advocated by many and are practiced in many countries now, frequently managed by national dental, otorhinolaryngeal, or $\mathrm{HN}$ oncological associations $[71,73]$.

\section{Limitations}

Due to limited resources, this review searched and included studies from three large commonly used databases only. Greater availability of resources and access may have allowed a wider search yielding more studies (published and unpublished) via other databases, web resources, and gray literature. There is also a possibility of having excluded some studies which reported/published insufficient data to meet the inclusion criteria of this review when these studies may have had adequate unpublished data. However, it was beyond the scope of this review to trace this data.

Though most of the studies were of strong quality, they differed in nature of population, study setting, cancer case definition, method of diagnosis of cancer, selection and type of controls, history of frequency of dental visits, method of data collection, and its analysis. Also, the positive association between never/irregular dental visits and incidence of cancer could be understated in our pooled estimate as this meta-analysis is conducted on case-control studies where recall and selection bias remains a concern. Another potential limitation is the varied distribution of frequency of dental visits among the studies. Unfortunately, not all dentists consider it mandatory to undertake a comprehensive examination of the oral and oropharyngeal soft tissues at the time of visits made for issues involving strictly dental problems, such as toothache or the need for dental restorations.

\section{Conclusions and implications for future research}

Oral health is a part of general health and quality of life. Targeted education to alert those at risk about OCs and other HNCs, and the warning signs, and better training coupled with opportunistic oral cavity examinations by dentists could reduce the burden of this disease. According to The American Cancer Society, a cancer-related check-up annually for all individuals aged 40 and older, and every 3 years for those between the ages of 20 and 39, should include health counseling and examinations for cancers of the oral cavity [74]. Despite the lack of support for population-based screening, opportunistic screening by thorough examination of the oral cavity and oropharynx should be carried out while treating or examining patients for other diseases, such as caries and periodontal disease. Among other ways, a safety net could be introduced by means of compulsory dental check-ups for disadvantaged people, for example those claiming social benefits.

\section{Glossary of terms}

Please refer to Table 6. 


\section{Appendix}

Table 1 Electronic database search strategy (August 2017)

PubMed

\# 1: Head and neck cancers [MH] OR head and neck neoplasms [tiab] OR oral cancers $[\mathrm{MH}] \mathrm{OR}$ upper aerodigestive tract cancers $[\mathrm{MH}] \mathrm{OR}$ cancer of tongue [tiab] OR cancer of oropharynx [tiab] OR cancer of hypopharynx [tiab]

\# 2: Dental visits [MH] OR visits the dentist [tiab] OR dental check-ups [tiab] OR dental examination [tiab] OR dental treatment [tiab] OR dental care [tiab] OR oral hygiene [tiab] OR periodontitis [tiab]

$\# 1$ and \#2 


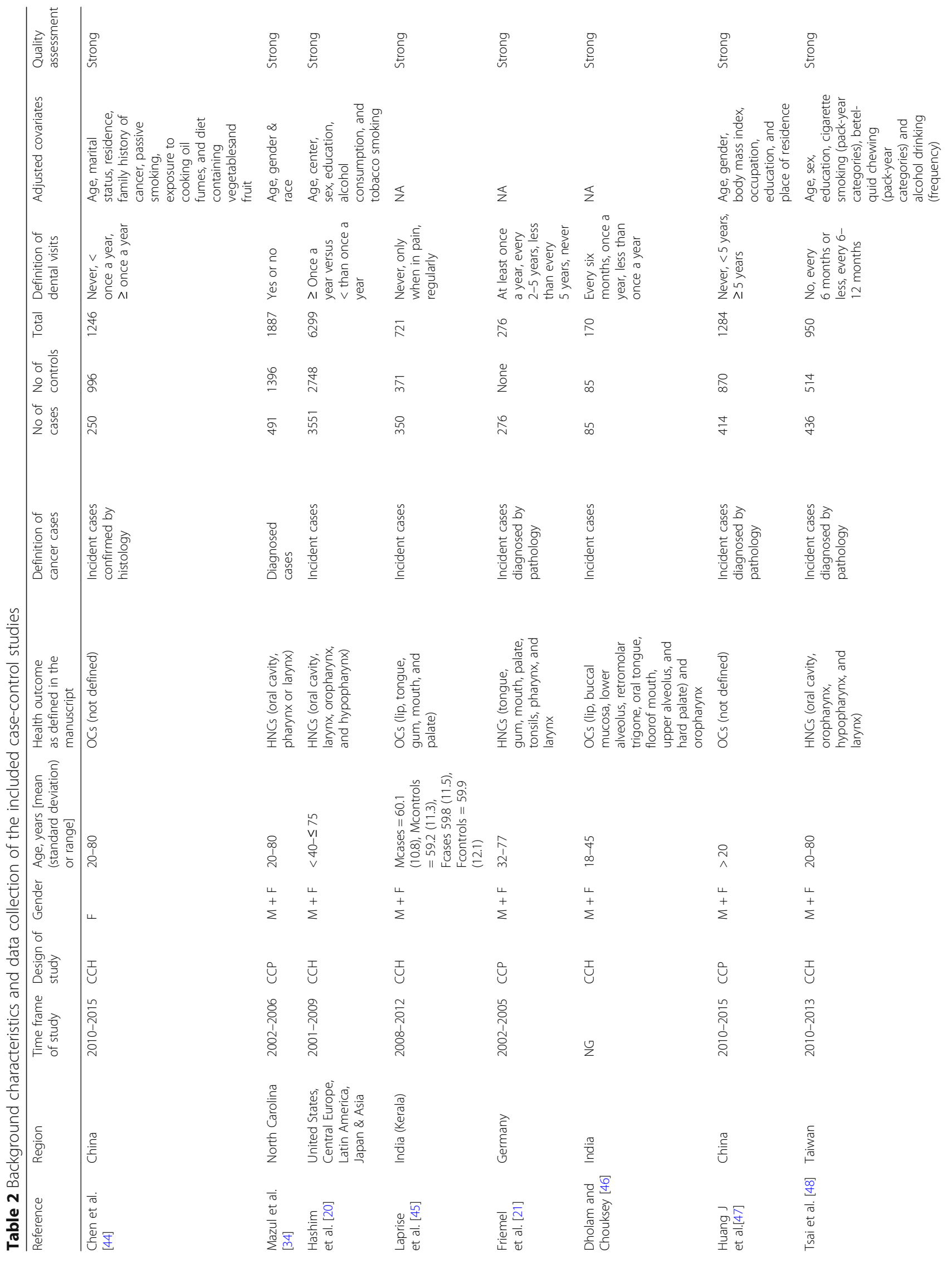




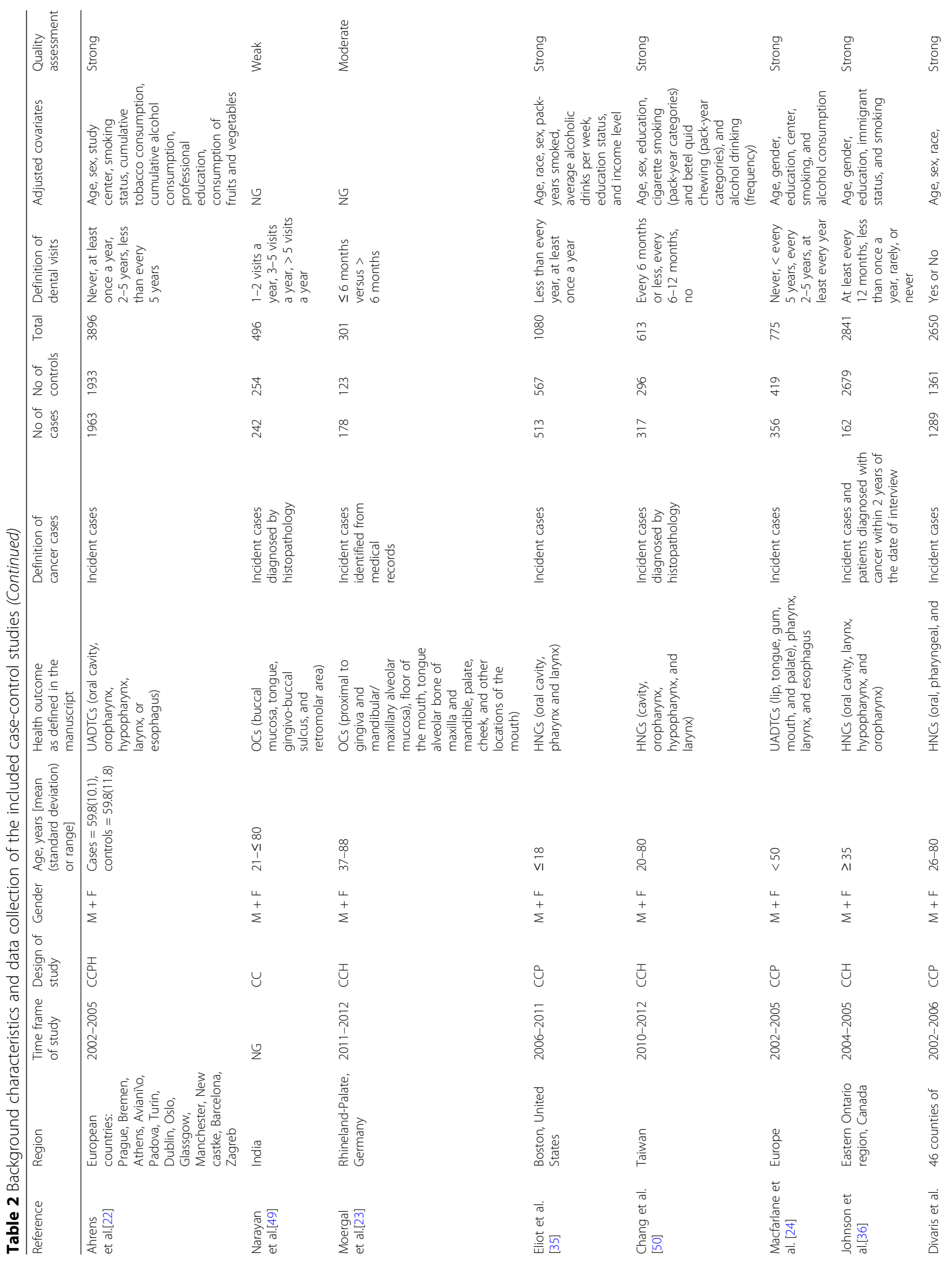


Gupta et al. Systematic Reviews $\quad$ (2019) 8:43

Page 12 of 18

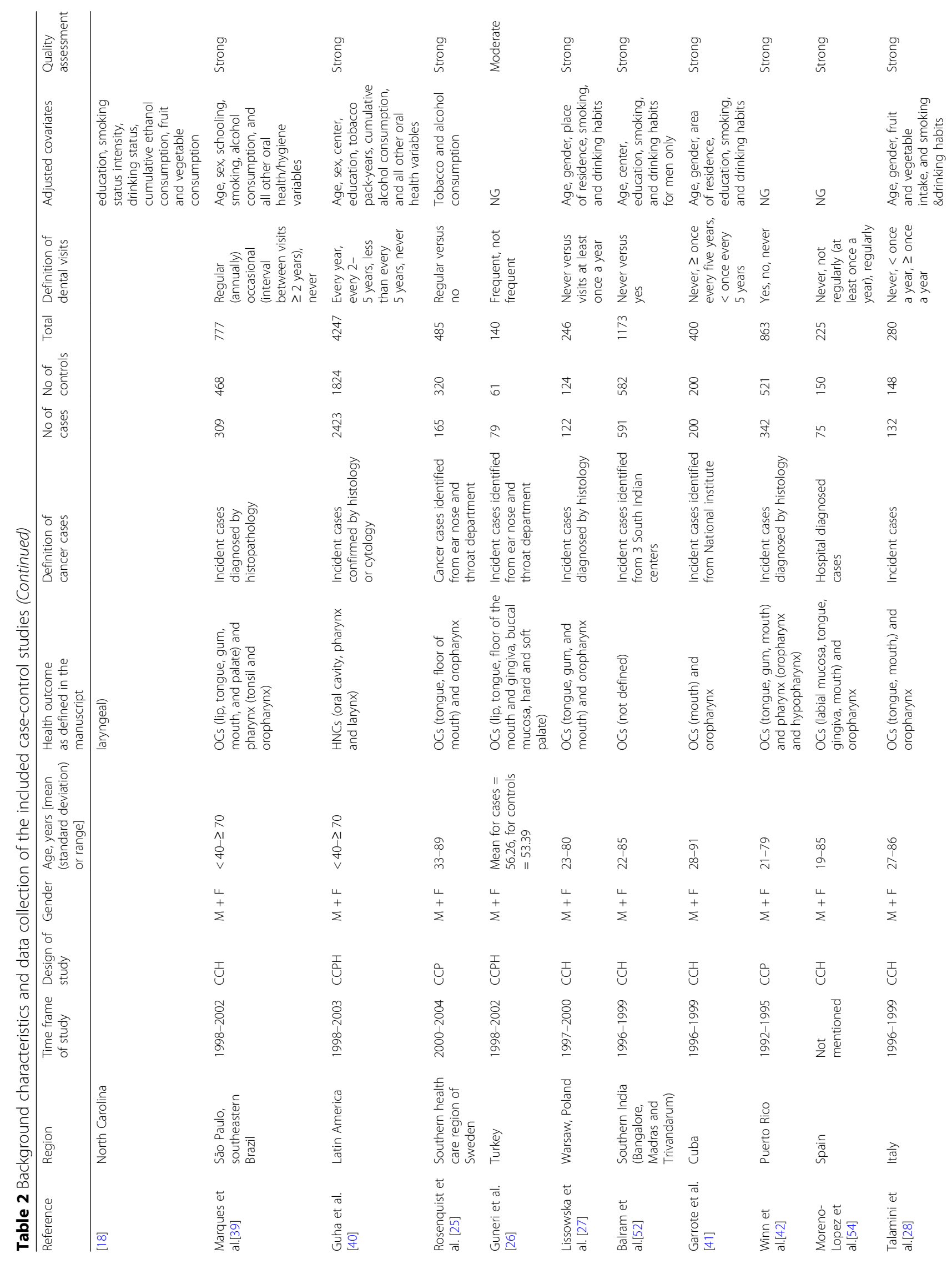


Gupta et al. Systematic Reviews

(2019) 8:43

Page 13 of 18

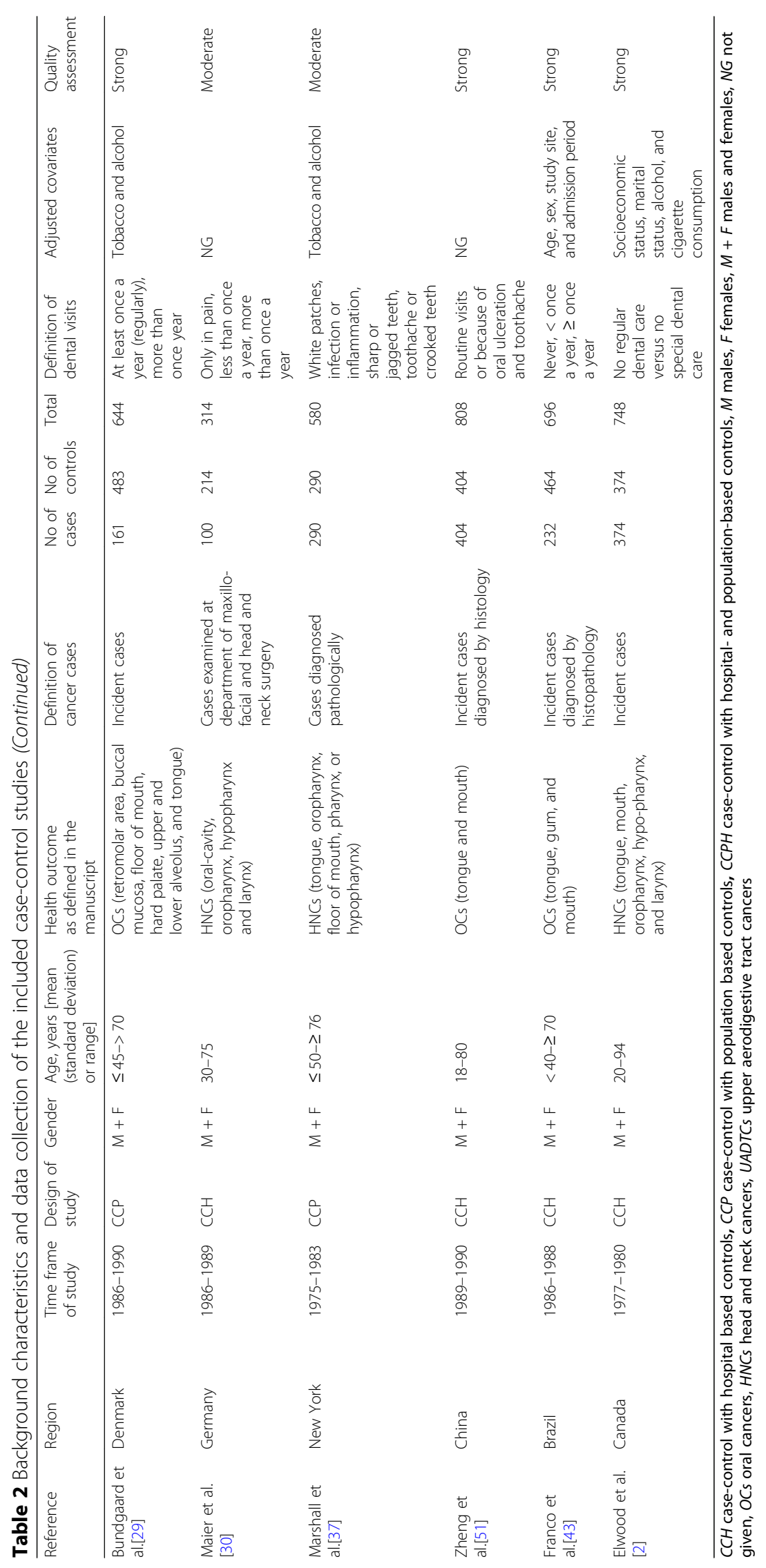




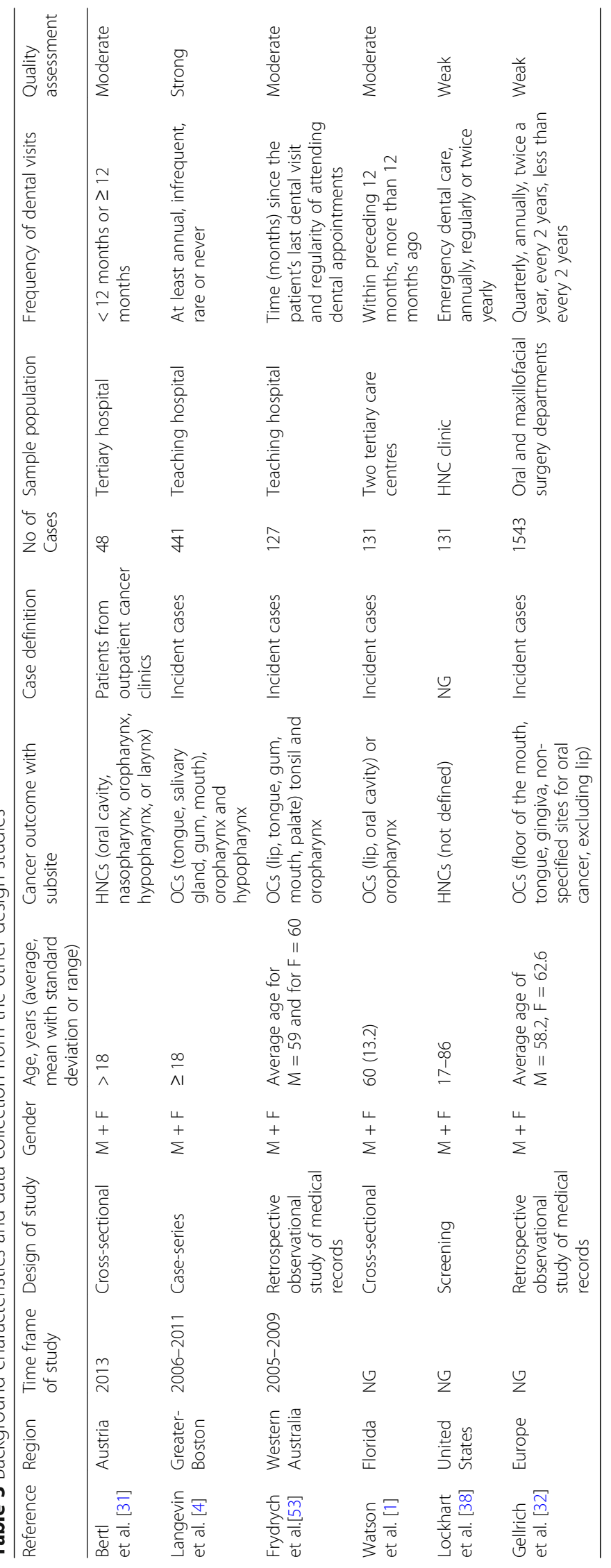


Table 4 Quality rating of the included studies according to Effective Public Health Practice Project's Qualitative Assessment Tool for Quantitative Studies

\begin{tabular}{|c|c|c|c|c|c|c|c|}
\hline Reference & Overall quality assessment & Selection bias & Study design & Confounders & Blinding & Data collection & $\begin{array}{l}\text { Withdrawals and } \\
\text { drop outs }\end{array}$ \\
\hline Chen et al. [44] & Strong & 1 & 2 & 1 & 2 & 1 & 1 \\
\hline Mazul et al. [34] & Strong & 1 & 2 & 1 & 2 & 1 & 2 \\
\hline Hashim et al. [20] & Strong & 1 & 2 & 1 & 2 & 1 & 2 \\
\hline Laprise et al. [45] & Strong & 2 & 2 & 1 & 2 & 1 & 1 \\
\hline Friemel et al. [21] & Strong & 2 & 2 & 1 & 2 & 1 & 2 \\
\hline Dholam and Chouksey [46] & Strong & 1 & 2 & 2 & 2 & 1 & 2 \\
\hline Bertl et al. [31] & Moderate & 2 & 3 & 2 & 2 & 2 & 2 \\
\hline Huang J et al. [47] & Strong & 1 & 2 & 1 & 2 & 1 & 2 \\
\hline Tsai et al. [48] & Strong & 2 & 2 & 1 & 2 & 1 & 2 \\
\hline Ahrens et al. [22] & Strong & 2 & 2 & 1 & 2 & 1 & 2 \\
\hline Narayan et al. [49] & Weak & 3 & 3 & 3 & 2 & 1 & 3 \\
\hline Moergal et al. [23] & Moderate & 3 & 2 & 2 & 2 & 1 & 2 \\
\hline Eliot et al. [35] & Strong & 1 & 2 & 1 & 1 & 1 & 2 \\
\hline Chang et al. [50] & Strong & 2 & 2 & 1 & 2 & 1 & 2 \\
\hline Langevin et al. [4] & Strong & 1 & 2 & 1 & 2 & 1 & 2 \\
\hline Frydrych et al. [53] & Moderate & 3 & 2 & 2 & 2 & 2 & 2 \\
\hline Groome et al. [3] & Strong & 2 & 1 & 1 & 2 & 2 & 2 \\
\hline Macfarlane et al. [24] & Strong & 2 & 2 & 1 & 2 & 1 & 2 \\
\hline Johnson et al. [36] & Strong & 1 & 2 & 1 & 2 & 1 & 2 \\
\hline Divaris et al. [18] & Strong & 2 & 2 & 1 & 2 & 1 & 2 \\
\hline Watson et al. [1] & Moderate & 3 & 2 & 2 & 2 & 2 & 2 \\
\hline Marques et al. [39] & Strong & 2 & 2 & 1 & 2 & 1 & 2 \\
\hline Guha et al. [40] & Strong & 2 & 2 & 1 & 2 & 1 & 2 \\
\hline Rosenquist et al. [56] & Strong & 1 & 2 & 1 & 2 & 1 & 2 \\
\hline Guneri et al. [26] & Moderate & 1 & 2 & 2 & 2 & 1 & 2 \\
\hline Lissowska et al. [27] & Strong & 1 & 2 & 1 & 2 & 1 & 2 \\
\hline Gellrich et al. [32] & Weak & 1 & 3 & 1 & 3 & 1 & 1 \\
\hline Balram et al. [52] & Strong & 1 & 2 & 1 & 2 & 1 & 2 \\
\hline Garrote et al. [41] & Strong & 1 & 2 & 1 & 2 & 1 & 1 \\
\hline Winn et al. [42] & Strong & 1 & 2 & 1 & 2 & 1 & 2 \\
\hline Moreno-Lopez et al. [54] & Strong & 2 & 2 & 1 & 2 & 1 & 2 \\
\hline Talamini et al. [28] & Strong & 1 & 2 & 1 & 2 & 1 & 2 \\
\hline Bundgaard et al. [29] & Strong & 1 & 2 & 1 & 2 & 1 & 1 \\
\hline Lockhart et al. [38] & Weak & 3 & 3 & 2 & 2 & 2 & 2 \\
\hline Maier et al. [30] & Moderate & 3 & 2 & 2 & 2 & 1 & 2 \\
\hline Marshall et al. [37] & Moderate & 3 & 2 & 1 & 2 & 1 & 2 \\
\hline Zheng et al. [51] & Strong & 1 & 2 & 1 & 2 & 1 & 1 \\
\hline Franco et al. [43] & Strong & 1 & 2 & 1 & 2 & 1 & 2 \\
\hline Elwood et al. [2] & Strong & 2 & 2 & 1 & 2 & 1 & 1 \\
\hline
\end{tabular}


Table 5 Meta-regression analysis

\begin{tabular}{|c|c|c|c|c|}
\hline Moderator & Coefficient & Standard error & $95 \% \mathrm{Cl}$ & $P$ value \\
\hline Never/ $\leq 6$ months, $>6$ months & Reference & & & \\
\hline Never, < once a year, $\geq$ once a year & -0.4954 & 0.3363 & $-1.1545-0.1637$ & 0.1407 \\
\hline Never, < every 5 years, every $2-5$ years, at least every year & -0.4048 & 0.3632 & $-1.1167-0.3072$ & 0.2651 \\
\hline Never, yes & -0.5807 & 0.3370 & $-1.3195-0.1581$ & 0.1234 \\
\hline Special dental care & -0.8194 & 0.5741 & $-1.9447-0.3059$ & 0.1535 \\
\hline Only in pain, no visits & -0.8008 & 0.5776 & $-1.9329-0.3312$ & 0.1656 \\
\hline $1-2$ visits a year, $3-5$ visits a year & -0.8132 & 0.5569 & $-1.9046-0.2782$ & 0.1442 \\
\hline
\end{tabular}

$R^{2}$ analog $=0.00$, test of the model: $P=0.6316$

Table 6 Glossary of terms

\begin{tabular}{ll}
\hline Cls & Confidence intervals \\
EPHPP & Effective Public Health Practice Project \\
HNCS & Head and neck cancers \\
HN & Head and neck \\
ICD & International classification of disease \\
MOOSE & Meta-analysis of Observational Studies in Epidemiology \\
$\mathrm{N}$ & Number of studies \\
OCS & Oral cancers \\
OR & Odds ratio \\
PRISMA & Preferred Reporting Items for Systematic Review and Meta- \\
& Analysis \\
UADT & Upper aerodigestive tract \\
\hline
\end{tabular}




\section{Acknowledgements}

Not applicable.

\section{Availability of data and material}

Not applicable.

\section{Funding}

No funding received.

\section{Authors' contributions}

BG contributed to conception or design. BG and NK contributed to acquisition in data extraction form. BG conducted the statistical analysis and interpretation of data. BG drafted the manuscript. BG, NK and NWJ critically revised the manuscript for important intellectual content. All authors read and approved the final manuscript.

\section{Ethics approval and consent to participate}

Not applicable.

\section{Consent for publication}

Not applicable.

\section{Competing interests}

The authors declare that they have no competing interests.

\section{Publisher's Note}

Springer Nature remains neutral with regard to jurisdictional claims in published maps and institutional affiliations.

\section{Author details}

${ }^{1}$ Torrens University, Adelaide, South Australia 5000, Australia. ${ }^{2}$ Department of Orthopaedics, Base Hospital, Lucknow, India. ${ }^{3}$ Menzies Health Institute Queensland and School of Dentistry and Oral Health, Griffith University, Gold Coast, Australia.

Received: 7 January 2018 Accepted: 14 January 2019

Published online: 04 February 2019

\section{References}

1. Watson JM, Logan HL, Tomar SL, Sandow P. Factors associated with earlystage diagnosis of oral and pharyngeal cancer. Community Dent Oral Epidemiol. 2009;37:333-41.

2. Elwood JM, Gallagher RP. Factors influencing early diagnosis of cancer of the oral cavity. Can Med Assoc J. 1985;133:651

3. Groome PA, Rohland SL, Hall SF, Irish J, Mackillop WJ, O'Sullivan B. A population-based study of factors associated with early versus late stage oral cavity cancer diagnoses. Oral Oncol. 2011:47:642-7.

4. Langevin SM, Michaud DS, Eliot M, Peters ES, McClean MD, Kelsey KT. Regular dental visits are associated with earlier stage at diagnosis for oral and pharyngeal cancer. Cancer Causes Control. 2012;23:1821-9.

5. Gupta B, Johnson NW, Kumar N. Global epidemiology of head and neck cancers: a continuing challenge. Oncology. 2016;91:13-23.

6. Pitiphat W, Diehl SR, Laskaris G, Cartsos V, Douglass CW, Zavras Al. Factors associated with delay in the diagnosis of oral cancer. J Dent Res. 2002;81:192-7.

7. Stefanuto P. Doucet JC, Robertson C. Delays in treatment of oral cancer: review of the current literature. Oral Surg Oral Med Oral Pathol Oral Radiol. 2014;117:424-9.

8. Lim K, Moles DR, Downer MC, Speight PM. Opportunistic screening for oral cancer and precancer in general dental practice: results of a demonstration study. Br Dent J. 2003;194:497-502. 493

9. Netuveli G, Sheiham A, Watt RG. Does the 'inverse screening law' apply to oral cancer screening and regular dental check-ups? J Med Screen. 2006;13:47-50.

10. Mashberg A. Diagnosis of early oral and oropharyngeal squamous carcinoma: obstacles and their amelioration. Oral Oncol. 2000;36:253-5.

11. LeHew CW, Epstein JB, Kaste LM, Choi YK. Assessing oral cancer early detection: clarifying dentists' practices. J Public Health Dent. 2010;70:93-100.

12. MacCarthy DD. Oral and neck examination for early detection of oral cancer a practical guide. J Ir Dent Assoc. 2011;57:195-9.
13. Mariño R, Haresaku S, McGrath R, Bailey D, McCullough M, Musolino R, et al. Oral cancer screening practices of oral health professionals in Australia. BMC Oral Health. 2017;17:151

14. Liberati A, Altman DG, Tetzlaff J, Mulrow C, Gotzsche PC, loannidis JP, et al. The PRISMA statement for reporting systematic reviews and meta-analyses of studies that evaluate health care interventions: explanation and elaboration. J Clin Epidemiol. 2009;62:e1-34.

15. Stroup DF, Berlin JA, Morton SC, Olkin I, Williamson GD, Rennie D, et al. Meta-analysis of observational studies in epidemiology: a proposal for reporting. JAMA. 2000;283:2008-12

16. Effective Public Health Practice Project (EPHPP). Qualitative assessment tool for quantitative studies 2003. [cited 2017 July 30]. Available from: https:// ink.springer.com/content/pdf/bbm\%3A978-3-319-17284-2\%2F1.

17. Borenstein M, Hedges LV, Higgins J, Rothstein H. Comprehensive metaanalysis version 2. Biostat Inc: Englewood, NJ; 2009.

18. Divaris K, Olshan AF, Smith J, Bell ME, Weissler MC, Funkhouser WK, et al. Oral health and risk for head and neck squamous cell carcinoma: the Carolina head and neck cancer study. Cancer Causes Control. 2010;21:567-75.

19. Elwood JM, Pearson JC, Skippen DH, Jackson SM. Alcohol, smoking, social and occupational factors in the aetiology of cancer of the oral cavity, pharynx and larynx. Int J Cancer. 1984;34:603-12.

20. Hashim D, Sartori S, Brennan P, Curado MP, Wunsch-Filho V, Divaris K, et al. The role of oral hygiene in head and neck cancer: results from international head and neck cancer epidemiology (INHANCE) consortium. Ann Oncol. 2016;27:1619-25.

21. Friemel J, Foraita R, Günther $K$, Heibeck M, Günther F, Pflueger $M$, et al. Pretreatment oral hygiene habits and survival of head and neck squamous cell carcinoma (HNSCC) patients. BMC Oral Health. 2016;16:33.

22. Ahrens W, Pohlabeln H, Foraita R, Nelis M, Lagiou P, Lagiou A, et al. Oral health, dental care and mouthwash associated with upper aerodigestive tract cancer risk in Europe: the ARCAGE study. Oral Oncol. 2014;50:616-25.

23. Moergel M, Kammerer $P$, Kasaj A, Armouti E, Alshihri A, Weyer $V$, et al, Chronic periodontitis and its possible association with oral squamous cell carcinoma-a retrospective case control study. Head Face Med. 2013:9:39.

24. Macfarlane TV, Macfarlane GJ, Oliver RJ, Benhamou S, Bouchardy C, Ahrens $W$, et al. The aetiology of upper aerodigestive tract cancers among young adults in Europe: the ARCAGE study. Cancer Causes Control. 2010;21:2213-21.

25. Rosenquist K, Wennerberg J, Schildt EB, Bladstrom A, Goran Hansson B, Andersson G. Oral status, oral infections and some lifestyle factors as risk factors for oral and oropharyngeal squamous cell carcinoma. A populationbased case-control study in southern Sweden. Acta Otolaryngol. 2005:125: 1327-36.

26. Guneri $P$, Cankaya H, Yavuzer A, Guneri EA, Erisen L, Ozkul D, et al. Primary oral cancer in a Turkish population sample: association with sociodemographic features, smoking, alcohol, diet and dentition. Oral Oncol. 2005:41:1005-12.

27. Lissowska J, Pilarska A, Pilarski P, Samolczyk-Wanyura D, Piekarczyk J, Bardin-Mikollajczak A, et al. Smoking, alcohol, diet, dentition and sexual practices in the epidemiology of oral cancer in Poland. Eur J Cancer Prev. 2003;12:25-33.

28. Talamini R, Vaccarella S, Barbone F, Tavani A, La Vecchia C, Herrero R, et al. Oral hygiene, dentition, sexual habits and risk of oral cancer. $\mathrm{Br} J$ Cancer. 2000;83:1238-42.

29. Bundgaard T, Wildt J, Frydenberg M, Elbrond O, Nielsen JE. Case-control study of squamous cell cancer of the oral cavity in Denmark. Cancer Causes Control. 1995:6:57-67.

30. Maier H, Zoller J, Herrmann A, Kreiss M, Heller WD. Dental status and oral hygiene in patients with head and neck cancer. Otolaryngol Head Neck Surg. 1993;108:655-61.

31. Bertl K, Loidl S, Kotowski U, Heiduschka G, Thurnher D, Stavropoulos A, et al. Oral health status and dental care behaviours of head and neck cancer patients: a cross-sectional study in an Austrian tertiary hospital. Clin Oral Investig. 2016;20:1317-27.

32. Gellrich N-C, Suarez-Cunqueiro MM, Bremerich A, Schramm A. Characteristics of oral cancer in a central European population: defining the dentist's role. The J Am Dent Assoc. 2003;134:307-14.

33. Moreno-Lopez LA, Esparza-Gomez GC, Gonzalez-Navarro A, Cerero-Lapiedra R, Gonzalez-Hernandez MJ, Dominguez-Rojas V. Risk of oral cancer associated with tobacco smoking, alcohol consumption and oral hygiene: a case-control study in Madrid. Spain. Oral Oncol. 2000;36:170-4. 
34. Mazul AL, Taylor JM, Divaris K, Weissler MC, Brennan P, Anantharaman D, et al. Oral health and human papillomavirus-associated head and neck squamous cell carcinoma. Cancer. 2017;123:71-80.

35. Eliot MN, Michaud DS, Langevin SM, McClean MD, Kelsey KT. Periodontal disease and mouthwash use are risk factors for head and neck squamous cell carcinoma. Cancer Causes Control. 2013;24:1315-22.

36. Johnson S, McDonald JT, Corsten M, Rourke R. Socio-economic status and head and neck cancer incidence in Canada: a case-control study. Oral Oncol. 2010:46:200-3.

37. Marshall JR, Graham S, Haughey BP, Shedd D, O'Shea R, Brasure J, et al. Smoking, alcohol, dentition and diet in the epidemiology of oral cancer. Eur J Cancer B Oral Oncol. 1992;28B:9-15.

38. Lockhart PB, Clark J. Pretherapy dental status of patients with malignant conditions of the head and neck. Oral Surg Oral Med Oral Pathol. 1994;77:236-41.

39. Marques LA, Eluf-Neto J, Figueiredo RA, Gois-Filho JF, Kowalski LP, Carvalho $M B$, et al. Oral health, hygiene practices and oral cancer. Rev Saude Publica. 2008:42:471-9.

40. Guha N, Boffetta P, Wunsch Filho V, Eluf Neto J, Shangina O, Zaridze D, et al. Oral health and risk of squamous cell carcinoma of the head and neck and esophagus: results of two multicentric case-control studies. Am J Epidemiol. 2007;166:1159-73.

41. Garrote LF, Herrero R, Reyes RM, Vaccarella $S$, Anta JL, Ferbeye L, et al. Risk factors for cancer of the oral cavity and oro-pharynx in Cuba. Br J Cancer. 2001;85:46-54

42. Winn DM, Diehl SR, Brown LM, Harty LC, Bravo-Otero E, Fraumeni JF Jr, et al. Mouthwash in the etiology of oral cancer in Puerto Rico. Cancer Causes Control. 2001;12:419-29.

43. Franco EL, Kowalski LP, Oliveira BV, Curado MP, Pereira RN, Silva ME, et al. Risk factors for oral cancer in Brazil: a case-control study. Int J Cancer. 1989; 43:992-1000.

44. Chen F, He BC, Yan LJ, Qiu Y, Lin LS, Cai L. Influence of oral hygiene and its interaction with standard of education on the risk of oral cancer in women who neither smoked nor drank alcohol: a hospital-based, case-control study. Br J Oral Maxillofac Surg. 2017:55:260-5.

45. Laprise C, Shahul HP, Madathil SA, Thekkepurakkal AS, Castonguay G, Varghese I, et al. Periodontal diseases and risk of oral cancer in southern India: results from the HeNCe life study. Int J Cancer. 2016:139:1512-9.

46. Dholam KP, Chouksey GC. Squamous cell carcinoma of the oral cavity and oropharynx in patients aged 18-45 years: a case-control study to evaluate the risk factors with emphasis on stress, diet, oral hygiene, and family history. Indian J Cancer. 2016;53:244-51.

47. Huang J, He B, Chen F, Liu F, Yan L, Hu Z, et al. Association between oral hygiene, chronic diseases, and oral squamous cell carcinoma. Zhonghua Yu Fang Yi Xue Za Zhi. 2015;49:688-92.

48. Tsai ST, Wong TY, Ou CY, Fang SY, Chen KC, Hsiao JR, et al. The interplay between alcohol consumption, oral hygiene, $\mathrm{ALDH} 2$ and $\mathrm{ADH} 1 \mathrm{~B}$ in the risk of head and neck cancer. Int J Cancer. 2014;135:2424-36.

49. Narayan TV, Revanna GM, Hallikeri U, Kuriakose MA. Dental caries and periodontal disease status in patients with oral squamous cell carcinoma: a screening study in urban and Semiurban population of Karnataka. J Maxillofac Oral Surg. 2014;13:435-43.

50. Chang JS, Lo HI, Wong TY, Huang CC, Lee WT, Tsai ST, et al. Investigating the association between oral hygiene and head and neck cancer. Oral Oncol. 2013:49:1010-7.

51. Zheng TZ, Boyle P, Hu HF, Duan J, Jian PJ, Ma DQ, et al. Dentition, oral hygiene, and risk of oral cancer: a case-control study in Beijing, People's Republic of China. Cancer Causes Control. 1990;1:235-41.

52. Balaram $P$, Sridhar H, Rajkumar T, Vaccarella S, Herrero R, Nandakumar A, et al. Oral cancer in southern India: the influence of smoking, drinking, paanchewing and oral hygiene. Int J Cancer. 2002;98:440-5.

53. Frydrych AM, Slack-Smith LM. Dental attendance of oral and oropharyngeal cancer patients in a public hospital in Western Australia. Aust Dent J. 2011; 56:278-83.

54. Moreno-Lopez L, Esparza-Gomez G, Gonzalez-Navarro A, Cerero-Lapiedra R, Gonzalez-Hernandez M, Domınguez-Rojas V. Risk of oral cancer associated with tobacco smoking, alcohol consumption and oral hygiene: a casecontrol study in Madrid, Spain. Oral Oncol. 2000;36:170-4.

55. Vandenbroucke JP, Pearce N. Case-control studies: basic concepts. Int J Epidemiol. 2012;41:1480-9.

56. Rosenquist K. Risk factors in oral and oropharyngeal squamous cell carcinoma: a population-based case-control study in southern Sweden. Swed Dent J Suppl. 2005;179:1-66.
57. Kamath A, Shashidhar KN, Anantharamaiah H, Rangareddy H, Sathyanarayana VB. Risk factors, lipid profile, and histopathological study of oral cancers in Kolar district: a case-control study. J Cancer Res Ther. 2014;10:171-5.

58. Hahn W. Clinical signs for the early recognition of cancer of the oral cavity. Int Dent J. 1977;27:165-71.

59. Amsel Z, Strawitz JG, Engstrom PF. The dentist as a referral source of first episode head and neck cancer patients. J Am Dent Assoc. 1983;106:195-7.

60. Kowalski LP, Franco EL, Torloni H, Fava AS, de Andrade SJ, Ramos G, et al. Lateness of diagnosis of oral and oropharyngeal carcinoma: factors related to the tumour, the patient and health professionals. Eur J Cancer B Oral Oncol. 1994;30b:167-73.

61. Gorsky M, Dayan D. Referral delay in diagnosis of oro/oropharyngeal cancer in Israel. Eur J Cancer B Oral Oncol. 1995;31b:166-8.

62. Holmes JD, Dierks EJ, Homer LD, Potter BE. Is detection of oral and oropharyngeal squamous cancer by a dental health care provider associated with a lower stage at diagnosis? J Oral Maxillofac Surg. 2003;61:285-91.

63. Chandu A, Smith AC. Patterns of referral of patients undergoing surgical management for oral cancer. Aust Dent J. 2002;47:309-13.

64. Scully C, Malamos D, Levers BG, Porter SR, Prime SS. Sources and patterns of referrals of oral cancer: role of general practitioners. Br Med J (Clin Res Ed). 1986;293:599-601.

65. Pogrel MA. The dentist and oral cancer in the north east of Scotland. Br Dent J. 1974;137:15-20.

66. Cooke BE, Tapper-Jones L. Recognition of oral cancer. Causes of delay $\mathrm{Br}$ Dent J. 1977;142:96-8.

67. Dimitroulis G, Reade P, Wiesenfeld D. Referral patterns of patients with oral squamous cell carcinoma, Australia. Eur J Cancer B Oral Oncol. 1992;28:23-7.

68. Messadi DV, Wilder-Smith P, Wolinsky L. Improving oral cancer survival: the role of dental providers. J Calif Dental Assoc. 2009;37:789-98.

69. Friedrich RE. Delay in diagnosis and referral patterns of 646 patients with oral and maxillofacial cancer: a report from a single institution in Hamburg, Germany. Anticancer Res. 2010;30:1833-6.

70. Warnakulasuriya KA, Johnson NW. Dentists and oral cancer prevention in the UK: opinions, attitudes and practices to screening for mucosal lesions and to counselling patients on tobacco and alcohol use: baseline data from 1991. Oral Dis. 1999;5:10-4

71. Leuci S, Aria M, Nicolo M, Spagnuolo G, Warnakulasuriya K, Mignogna MD. Comparison of views on the need for continuing education on oral cancer between general dentists and oral medicine experts: a Delphi survey. J Int Soc Prev Community Dent. 2016;6:465-73.

72. Walsh T, Liu JL, Brocklehurst $P$, Glenny AM, Lingen M, Kerr AR, et al. Clinical assessment to screen for the detection of oral cavity cancer and potentially malignant disorders in apparently healthy adults. Cochrane Database Syst Rev. 2013:11:CD010173.

73. Horowitz AM, Drury TF, Goodman HS, Yellowitz JA. Oral pharyngeal cancer prevention and early detection. Dentists' opinions and practices. J Am Dent Assoc. 2000;131:453-62.

74. Neville BW, Day TA. Oral Cancer and precancerous lesions. CA Cancer J Clin. 2002:52:195-215.

\section{Ready to submit your research? Choose BMC and benefit from:}

- fast, convenient online submission

- thorough peer review by experienced researchers in your field

- rapid publication on acceptance

- support for research data, including large and complex data types

- gold Open Access which fosters wider collaboration and increased citations

- maximum visibility for your research: over $100 \mathrm{M}$ website views per year

At $\mathrm{BMC}$, research is always in progress.

Learn more biomedcentral.com/submission 